\title{
Metamorphosis of Confucian Heritage Culture and the possibility of an Asian education research methodology
}

\author{
Jae PARK 1 \\ Faculty of Education \\ The University of Hong Kong \\ Hong Kong, China
}

\begin{abstract}
This paper opens with a critical analysis of a paradox in contemporary educational research in and about Confucian Heritage Culture (CHC): The assumption that national boundaries coincide with that of a distinct and homogeneous culture, which consistently renders rather homogenous set of educational phenomena, collides against a more widely accepted discourse-culture transcends geographical frontiers and is ever evolving in character. It is claimed that this paradox is due to the fact that a thin conception of $\mathrm{CHC}$ competes neck to neck with a thick conception of it. This paper also addresses the possibility of an ad hoc education research methodology in and about $\mathrm{CHC}$ and its compliance issues regarding the mainstream Western research dynamics and philosophy of science. Confucian elements relevant to $\mathrm{CHC}$ research rationale are discussed to argue that first, a research is inextricably a moral act insofar free actors are involved in it, second, most sui generis methodological problems attached to $\mathrm{CHC}$ occur in the sphere of ethics and, third, a research methodology that takes into account phenomenographic variation could be the best suited to ease emic-etic tensions inherent to CHC-based research.
\end{abstract}

Keywords: research methodology, Confucian Heritage Culture, evolving Confucianism, emic-etic tension, philosophy of science

${ }^{1}$ Email: jaepark@hku.hk 


\section{Introduction}

For long time, educationalists have speculated on the role of culture in education leaving no stone unturned. Whitehead (1967) could never have suspected that one day mathematics education, his paradigm for specialized knowledge as distinct from cultural knowledge will also be a subject matter for cultural inquiry (Ref. Bishop 1988). The related literature is abundant and often incongruous, for instance, education as instrument of cultural struggle and symbolic violence (Freire 1972; Bourdieu and Passeron 1977) versus culture as the principal due and goal of education since it should usher the young to understand and live in it (Bruner 1996). Emerging situated and contextual discourses in education treats culture as one of the most prototypical contexts that permeates all other domains and it is per se an independent area of research or unit of analysis. Also termed in plural, Confucian Heritage Culture (CHC) is described by education research communities as a group of Asian nation-states with their motherland and overseas diasporas who share Confucian values, which consistently reflect in social behaviour and practices, including academic outcomes and learning approaches (Watkins, Reghi, and Astilla 1991; Biggs et al. 1996; Chan and Rao 2009; Tweed and Lehman 2002; Li 2003). Despite its relatively short trajectory, CHC discourse has produced fruitful academic discussions. One such argument has been on the Western misperception of education in CHC partly due to their dichotomous research paradigms that are inappropriate for research in and about $\mathrm{CHC}$ (Watkins, Reghi, and Astilla 1991; Biggs et al. 1996; Chan and Rao 2009). It posts a valid concern on whether CHC-based researches can or should have a distinct process of inquiry, which calls for critical analysis. I put to fore a theoretical analysis on the possibility of an Asian education research methodology and conjecture what kind of conditions such a methodology should meet if it were to produce plausible and fruitful researches, and not misinterpretation-prone, methodologically troubling or of dubious validity.

The present analysis could be considered as more heretical than critical. As an ethnic Korean who has always been exposed to one of the strictest Confucianism in Asia, I could be considered as an insider in $\mathrm{CHC}$, yet by training, academic interests and more years of living in overseas diaspora communities, I might be seen as taking an outsider stance. This disagreeing cultural exposure could be both weakness and strength of this paper. 


\section{Confucian Heritage Culture, thin and thick}

Although not all CHC educational researches are cross-cultural or international comparative education researches, they share some common methodological concerns. Either refers to the impact of cultural nuances on multiple domains and calls for caution when a methodology is applied cross-culturally. According to Mason (2007), the difficulties associated with cross-culturally applied methodology can be summarized as: (1) the misleading modern construe of national cultures; (2) ethnography usually contains phenomenological data from actors, participants and researcher, with almost no heed to neo-Marxian sort of socio-political critique; (3) ethnographic researches seldom offer the perspective of cultural outsiders (LeVine 1966); and (4) ahistorical-ness of ethnography in general.

'National cultures' construe relies on an assumption that national boundaries ${ }^{2}$ coincide with that of a distinct and homogeneous culture that renders a rather homogenous score of phenomena unique to education, which collides against a more widely accepted discourse that culture transcends nation-state frontiers and is ever evolving in character. CHC has evolved is evolving and always immersed in a context, that is, situated in space, time, history and social structures. Hence, Japanese CHC before and after the Meiji ishin are different; post-World War II Japanese CHC contrasts with Korean CHC suffering the consequences of the Treaty of Versailles under Japanese colonialism. These two in turn are different from Chinese CHC. When examining the cultural and political influence on Chinese trade, which doubtlessly forged power structure of the Ming-Qing dynastical transition, Wang Gungwu (2001) distinguishes a high Confucianism from a popular Confucianism. High Confucianism was doctrinally archaic and it was preached by imperial literati and bureaucrats. Popular Confucianism was syncretic, alternating at convenience Confucian family/clanbased practices with Taoist and Buddhist practices. The shang (商 merchant) class rose and succumbed with Zheng Zhilong's private trade empire with the victory of Qing navy in 1683. This led Qing dynasty to re-impose archaic Confucian values in an attempt to stabilize the new empire, to be harshly persecuted again in the twentieth century during the May Fourth movement and the Cultural Revolution of Mao.

The ways how $\mathrm{CHC}$ was introduced and assimilated in other Asian regions were

\footnotetext{
2 In his seminal work, David Ho listed only Far East Asian nations, namely China, Japan and Korea and oversea minorities such as Chinese-American (Ho 1994, p. 286)
} 
equally heterogeneous. The Korean version of Chinese civil examination was introduced during tenth century Koryo to be definitely abolished during the Gap-oh reform (1894) of late Chosen, which coincided with the end of formal religion-like Confucianism or Yu-kyo (儒教 Confucian religion/code), a term that prevailed in Chosen Korea over its original Chinese Yu-ga (儒家 Confucian school) or Yu-hak (儒學 Confucian study). In Japan, kami and buddhas were replaced by Confucianism during Muromachi period (1333-1568) when people became more this-worldly than afterlifeconcerned transcendentalists (Ama 2005). It would be incorrect, however, to regard kata (型 form) that have pervaded all walks and aspects of Japanese life, from trade to suicide code (De Mente 2005), as totally CHC. Indeed, Confucian share in Japanese shikata (way of doing things) is open to discussion. Moreover, inside a kingdom or region reputed as $\mathrm{CHC}$, non-Confucian minorities have coexisted with their unique ways of organizing and leading life, continuously generating self-imageries and stereotypes. Some of these social imageries were not Confucian at all, such as the Uyghurs and Dungans in the Chinese-Kyrgyz-Kazakh borderlands. In some other cases, an opposite phenomenon of entrenchment occurred, such as the case of 'deep-seated' educational values of Korean ethnic minority in Chinese Liaoning province (Gao 2010). These facts corroborate the hypothesis of an acculturation process (Berry 2003), namely 'de-Confucianization' (Rozman 2002) of some CHC elements, whilst some others have remained rather stable in time, place, history and social structures. I call them respectively a thin $\mathrm{CHC}$ discourse and a thick $\mathrm{CHC}$ discourse, not as two poles for a snapshot analysis but as either shore of a flowing river for a contextual analysis. A thin CHC discourse as argued here is a socially constructed unity, an evolving category, hence always situationally specific (cf. Lowe 1996, p. 82) and bears lighter forms of Confucian cultural values with only meagre to modest resemblance to classic Confucianism. A thick $\mathrm{CHC}$ discourse, on the other hand, meets the following three principles:

- It should uphold some clearly distinct Confucian elements such as tao (道 way), jen (仁 humanity) or $l i$ (禮 rite, social ceremonials and conventions)

- These elements should exist across more than one geographical regions and borders, to ensure that they are not folktales

- These elements can be traced back to textual Classics of Confucius or widely recognized Confucian schools

Let me illustrate the foregoing with a case of thick CHC discourse. David Ho (1994) 
suggests that certain Confucian values can explain cognitive socialization of Asian students in America, namely a family-based cognitive conservatism. He argues that much of education achievement of CHC students has its root in an authoritarian moralism and collectivism that can be called parental conservatism. Confucian filial piety is, he claims, the origin of cognitive socialization (chiefly parental conservatism) of CHC students and this fact could decode the paradoxes surrounding CHC learners ( $\mathrm{p}$. 302). Ho's research work fulfils the criteria for a thick CHC discourse: Asian people in several regions and areas share a distinct Confucian element, i.e., hsiao (孝 piety), which is textually Confucian. What he does not mention though is the fact that filial piety was a later development in China. In the earlier teachings of Confucius, hsiao appears as a minor corpus linked to the concept of jen and piety towards ancestors or dead parents (cf. Waley and Confucius 1938, pp. 38-39). Hsiao's connection to sociopolitical paternalism was constructed roughly three to four centuries after the death of Confucius. The association between hsiao and the collective sphere occurred in China during Han dynasty when rulers instrumentalized $\mathrm{CHC}$ for socio-political stability (Liu 1998). Many elements of Korean CHC were also turned into political tools by the kings of Koryo dynasty (918-1392), but it was in Chosun dynasty (1392-1910), especially 1650 onwards, that Confucianism became both the political system and a quasi religion dictating a class-based apartheid, arranged marriages between clans and filial piety (only father-son) over conjugal affinity as the basis of family structure (Park and Cho 1995). Japanese CHC took a non-Confucian-like turn clashing against Buddhism during Tokugawa period when "being intellectual meant being a Confucian [and in] order to be a good Confucian, one had to avoid other religions; Buddhism was thus never accepted"(Ama 2005, p. 21). Elements of such politicised CHC are, of course, present in our days. Liu Shuxan summarized thus the end-result of the foregoing metamorphosis of $\mathrm{CHC}$ and as compared with the West:

It is...not true to say that the Confucian tradition does not value the individual, as everything must start with the individual. What is lacking is the kind of rugged individualism of the West. Everyone is conscious of a strong sense of responsibility to society; there is no dichotomy between the individual and the society, or the internal and the external. (1998, p. 59)

A thin $\mathrm{CHC}$ discourse in contemporary education and social science research diverge from classic Confucianism. Hofstede's famous ‘Confucian dynamism' (1991) argues that it is possible to identify a long-term orientation and a short-term orientation of Chinese 
people's social motivation, behaviour and action. His sociology upholds that when Confucian heritage people foster virtues they are aiming at rewards and 'Confucian dynamism' is a 'dimension of national cultures'. There are other analogous thin discourses with the common assumption that national boundaries can encapsulate all cultural nuances of CHC such as 'chopstick cultures' and 'chopstick area' (Funabashi 1993).

A consequence of this double entendre is that thin and thick $\mathrm{CHC}$ discourses can coexist side by side in a same educational research field, in the same body of work of a researcher, in a same book chapter and article.

\section{Methodological Issues in CHC-based Research}

The main discussion on CHC-based educational research and the possibility of an 'Asian education research methodology' is on research dynamics. By research dynamics, I mean the research rationale and ensuing action, that is, from deciding a unit of inquiry through choice of research framework to fieldwork and analysis.

A research framework comprises a conceptual component and an outlook, a body of a pre-existing theory or its modified version, also called naively as paradigm, which provides the researcher with an epistemic coherence throughout all the stages of an inquiry. In my view, this and equivalent 'Western' research dynamics and their basic rationale are sine qua non conditions to which any $\mathrm{CHC}$-based educational inquiries should pledge. Indeed, CHC-based researchers have no other option but to comply with any of time-honoured 'Western methodologies' because only by doing so their work could get recognition both intra-culturally and trans-culturally. If their researches are to deserve any attention, they should also make sense to, say, Central Asian, African and Latin-American heritage cultures and world research community at large. No one can take lightly Polanyi's principle of mutual control, "simple fact that scientists keep watch over each other" (1983, p. 72). If Western misconceptions on CHC and Eastern difficulties to project contextually sensitive self-imageries to the West were real, they would be due to a Western naturalistic coherence's pretence of universalism and its forgetfulness to take into account cultural variations and, Eastern inability to deliver a substantive and convincing discourse. The common fault of either side is an insufficient understanding of cultural variables. Jin $\mathrm{Li}$ argues, for example, that the problem lies in a "continual reliance of researchers on Western concepts without considering indigenous or emic cultural meanings and their psychological manifestations" (Li 2009, 
p. 42). She adds other three predicaments: (1) dichotomous conceptual frameworks of the West (2) dominant Western individualistic and culture-free anthropological assumptions (3) understanding education univocally as a means to social mobility (Li 2009).

These predicaments, however, do not seem to be exclusive of the West. Asian researchers of both Asian and Western backgrounds do not seem to be especially immune as many of them were trained either in the West or in heavily 'Westernized' academic environments in Asia. Moreover, even those who were not, won't be able to break free from Western philosophies of science, professional ethos and fora, all of which, to be straightforward, converge in to the prevailing Western Anglo scholarly publication bottleneck. This is not to say that these researches have less validity but, rather, to say that they usually use the same dichotomous conceptual frameworks when finger pointing 'Western misunderstandings'. The empirical research series on the "Paradox of the Chinese Learner" by Biggs and Watkins is an example (cf. Biggs et al. 1996) (Watkins, Biggs, and Comparative Education Research Centre. 2001). If the CHC discourse were a malaise, then it would be a global pandemic affecting both the West and the East.

In order to analyse critical areas of CHC-based research methodology when complying Western research requirements, I choose Karl Popper's tetradic schema for knowledge growth. It is preferred over Baconian inductive models because first, not all CHC educational research methodologies must be inductive, such as research on art critiquing education that uses a deductive method-general aesthetic notions allow interpretation of particular cases (Eisner 1985) and, second, because it is a research model that can put to rest the preoccupation and ambition for total generalization and total prediction that still haunt some educational research circles. Popper sketched his schema like this (1963):

$$
\mathrm{P}_{1-->} \mathrm{TT}_{1-->} \mathrm{EE}_{1-->} \mathrm{P}_{2-->} \infty
$$

In plain language, a researcher finds an intriguing problem $\left(\mathrm{P}_{1}\right)$; to solve it $\mathrm{s} /$ he tries out a first tentative theory $\left(\mathrm{TT}_{1}\right)$, after which, errors are eliminated $\left(\mathrm{EE}_{1}\right)$ to become aware of an ensuing problem $\left(\mathrm{P}_{2}\right)$. This unending process known as falsification is ultimately an 'ever discard errors' or 'problem solving by trial and error' heuristics-the quintessence of Popper's philosophy of science, epistemology and social theory. 
I now expand the preceding to pinpoint how ethical issues and methodological issues overlap in a research.

The act of singling out a research problem $\left(\mathrm{P}_{1}\right)$ from hundreds on the phenomenological horizon of researcher depends on the exercise of researcher's freedom and choice. Bewilderment or sense of wonder ${ }^{3}$ is the initial lead to his/her choice of one or more research problems, followed by an act of assigning a subjective relevance and category to each. The act of choosing and delimiting a research problem while dismissing all others, and not changing it lightly without having it tested, implies a free and rational agent and his/her moral act. Ethical-methodological problems are already apparent at this stage, for example, turning research participants into a 'case' or a 'research problem', i.e., the risk of 'problematizing' or 'pathologizing' them (Nind et al. 2004). In a broad sense, the entire $\mathrm{CHC}$ discourse is about 'problematizing' Asian children by categorizing them (e.g., deep or superficial learner) following researcher's mental rubric. At the very start of the research, a process of 'cultural invasion' and disruption of $l i$ that pervades all aspects of life in $\mathrm{CHC}$ societies could take place. "Rite brings out forcefully not only the harmony and beauty of social forms, the inherent and ultimate dignity of human intercourse; it brings out also the moral perfection implicit in achieving one's ends by dealing with others as beings of equal dignity, as free coparticipants in $l i$ " (Fingarette 1972, p. 16).

There is more than one tentative theory (TT) or methodology available to the researcher. Is s/he completely free to choose any? Popper's answer is surprisingly illiberal. He says that the fittest theory should be chosen. The predicament here is that all available theories are in the still-to-be-tested stage and no test result is known, and there can be neither inner certainty nor outer justification for its adequacy. At this point, Popper's argument takes a subtle turn: "the testing of a theory depends upon basic statements whose acceptance or rejection, in its turn, depends upon our decisions. Thus, it is decisions which settle the fate of theories" (Popper, 1959, p. 108). The type of decision he is referring to is a free decision:

With the conventionalist I hold that choice of any particular theory is an act, a practical matter...I differ from positivist in holding that basic statements are not justifiable by our immediate experiences, but are, from logical point of view, accepted by an act, a

\footnotetext{
3 The beginning of inquiry is aporia, the act of marvelling. First described by Plato in his Socratic dialogue Theaetetus (155d) and then by Aristotle in his Metaphysics (995a24-b2), aporia is openness and active inclination toward truth without feeling comfortable with things taken for granted.
} 
Researcher's freedom plays a key role in the choice of a theoretical framework and, not only that, freedom is the ultimate justification of why a researcher chooses a theoretical framework and not any other. This is not to say that the naturalistic criteria to choose a theoretical framework are to be neglected. By naturalistic criteria I mean something like, "empirical adequacy, or squaring with observational evidence, consistency, simplicity, comprehensiveness, explanatory unity, fecundity and learnability" (Evers and Lakomski 2001, p. 503) or any other rational choice of theoretical framework equivalent to that of Thomas Kuhn (1977). Choice of a theoretical framework should be purposeful and rational, yet it ultimately depends on freedom. This is the same ground on which Kuhn, Lakatos and Feyerabend together with Popper have been loosely tagged as irrationalists (Stove 1982). Immanuel Kant's dualism of freedom-moral law provides us with clues to understand the intriguing relationship between free decision and the fittest theory. His second Critique states, "freedom is indeed the ratio essendi of the moral law, the moral law is the ratio cognoscendi of freedom" (1997, p. 4). A vernacular reading could be: Moral law exists because of human freedom, and the reason why we try to know about our freedom is because there is a moral law that keeps our freedom in check. It also suggests mutual dependence between freedom and moral law on existential and epistemological grounds. Then, Kant himself defines freedom quite cryptically towards the end of his productive life, in a remote footnote of his Anthropology from a Pragmatic Point of View as briefly as "pure spontaneity" (2006, p. 30). This is the converging point of ethical issues and methodological issues in research, which suggests that critical issues in research methodology occur wherever and whenever any moral interactions take place among research actors. As the stage of tentative theory testing includes research framework formulation, fieldwork, and data collection, it is especially rich in interpersonal relationships. Two issues might be especially relevant to CHC-based research. First, it is just impossible to do a CHC research without any 'research biases', or the other way around, "researchers cannot observe another society or culture a-theoretically" (Mason 2007, p. 194). To some extent, every research framework itself is a bias. Second, with their jang (讓 yielding) as opposed to confronting and ch'ih (恥 shame) but not quite Western sense of guilt for committed fault (Fingarette 1972) (Fingarette 1979); or, Japanese kata as interpersonal negotiation strategies, fieldwork with $\mathrm{CHC}$ research participants could post some perplexing difficulties to Western research. A continuum of etiquette-ethics could silently yet critically distort the research process, everything from planning stage to 
participant's consent through interview turnout and outcome, even in experimental research (cf. Brashen 1974).

After testing the chosen theory, research outcomes are analysed. Karl Popper argues that in science, knowledge is acquired by error elimination (EE), the act of discarding wrong hypothesis or false theories, which failed to solve the problem (or, for disciplines similar to sociology and education, theories that failed to upgrade understanding or has no better descriptive power compared with previous ones). In Darwinian biology, one of the favourite examples of Sir Karl, when tentative solution (mutation) does not work, the error elimination turns out to be fatal "for the bearer of the mutation, for the organism in which they occur" (Popper 1999, p. 5). Although not so extreme, error elimination stage seems not less critical for educational research and cross-cultural comparative education inquiries in particular. Researchers face a moral dilemma at this later stage of research-either discarding errors together with failed theories or dragging them on. The dilemma is whether the researcher could recycle a theory that failed to solve the problem that bewildered him/her at the start of the research project.

Is the field of education invulnerable to this critical view of science and research methodology? Let us take a closer look. A typical education research is already confined to limited number of areas of inquiry (e.g., 'assessment' 'administration-policy' or 'language education') where researchers are usually hijacked by their own specialisms for decades, even perhaps for life. Possible imagery here is that of a furrowed forehead scholar committed to a fixed and small set of research problems and frameworks replicating inbred variables (disciplines, cultures, social sectors and organizations), digging the same pit for life. Many of these researches will claim some positive and enlightening outcome contributing to a field, or, as metaanalyst John Hattie has recently described, the 'what-works-recipe' or "theories of their own about what works (for them)" (2009, p. 3) in an academic world that is frantically publication-centred and output-dependent, and perhaps a faculty of education becoming a 'faculty of publication' (Ref. Adler and Harzing 2009). Reality-check, selfcriticism and laments aside, whatever is the reason, the fact is that it is not common at all that a second and a third frameworks are tested in sequence, in the same research.

Any attempt to reconcile forcibly the emerging data with failed hypothesis or theoretical framework would mean a regress for the research, if not a full-fledged deception. This wide-awake procrastination in eliminating errors is akrasia ${ }^{4}$, an

4 Self-indulgence is not the same as akrasia, which is a dissociation of rational decision and will: 
enigma of moral philosophy, a failure in self-dominion or lack of drive (free will) to follow the dictates of reason or, in our case, scientific rationality.

Popper says that after $\mathrm{EE}_{1}$ a new problem $\left(\mathrm{P}_{2}\right)$ emerges (cf. Popper 1972, p. 288). It seems that the term emergence is probably a misnomer here since an offspring-problem is not spontaneous but an ensuing version of an earlier one. What has fallen into researcher's lap is then the 'tail' of the first cycle rather than the 'head' of the second. The same 'tail' is the result of the inquiry process that has just ended, because the researcher upheld rational and ethical rigor of scientific inquiry. The transformation of that 'tail' into the 'head' of the second cycle can occur if the researcher freely and consciously decides to take it on, that is, it also has ethical implications. If all right, a second cycle of the schema can start, granted that the researcher so wishes and freely.

\section{Emic/Etic Tension in CHC-based Research}

My main claim in the foregoing discussion on a prototypical Western research dynamics is that a research is inextricably a moral act insofar free agents intervene and act in each and every stage of it, and not only when, for example, researchers are working on the ethical committee clearance at institutional level. In this section, I examine its corollary: sui generis methodological problems in CHC-based research are related to or occur in the sphere of ethics.

Among methodological issues in CHC-based Research, one deserves particular attention-interpretive intervention. When an interpretivist researcher has not been exposed sufficiently to the culture in situ, s/he should be especially attentive wherever and whenever an interpersonal relationship occurs. Taylor and Waldrip (1999) suggested some practical advises to interpretivist research: A tightly organized initial contact with local participants; prolonged engagement and observation; understanding the connection between ownership of knowledge (information) and social hierarchy; validating interviews with careful triangulation; overcoming language barriers; and keeping the interview process sustainable by being aware of local culture, for example, gender-related misunderstandings. Much earlier, John Berry suggested a three-stage adjustment for cross-cultural ethnography (1969): A first stage of determining

a self-indulgent person is deliberately (prohairoumenos) led about [by his desires], accepting that 'I should always pursue the pleasure that's before me'; an akratic person in contrast does not accept this, yet he pursues it anyway. (Aristotle, Nicomachean Ethics 1146b23-4) 
functional equivalence on either side of cultures under study. A functional equivalence is a social behaviour which "has developed in response to a problem shared by two or more social/cultural groups, even though the behaviour in one society does not appear to be related to its counterpart in another society" (p. 122). Berry's functional equivalence bears a resemblance to 'dimensions of national cultures' of Hofstede, who took cue from ethnographers who were contemporaries with Berry (1991, p. 13). Berry's second and third stages of adjustment for cross-cultural ethnography are identifying descriptive categories (equivalent to taxonomy or rubrics in education) and creating an adequate measuring instrument.

Conducting education research in $\mathrm{CHC}$ requires comparable demands in all interpersonal contact points, while high standards of fairness, trust and acceptance by locals are ensured. All translated research tools such as interview questionnaires, research instruments and inventories should enjoy reliability by verifying their internal consistency and stability in time (Brislin 1986; Behling and Law 2000; Vallerand et al. 1992; Banville, Desrosiers, and Genet-Volet 2000). CHC-based field research should ideally be in native language, assuming that any translations denote liability.

The apologia for 'outsider research' by David Bridges (2001) takes a different approach to the problem. He rightly describes that an outside research could easily be stereotyped by insiders as intrusive, disrespectful and disempowering because "an outsider cannot understand or represent accurately a particular kind of experience" (p. 372). But, he continues, outsider research can still contribute to understanding of all parties involved and inhibiting outsider research would only cause an epistemological and moral isolation (p. 381). He justifies outsider research by pointing out that experience of insider and its representation by outsider are simply different and none has special authority in validity (p. 374) and ends up by adding that an ideal condition for outsider research could be achieved by including cordiality, respect, openness to criticism and so on (p. 384). Although his diagnosis of the problem is correct, I disagree with Bridges's proposed solution on two grounds. First, his conditionals belong to the world of prospects and ideals, which cannot be naturalistically coherent and simplest (Ockham's razor) and, second, the chief problem that worries Bridges, namely emic/etic tension, needs a methodological solution and he does not address it. In my view, the core of methodological problems is the disparity between phenomenon as experienced and graphein (Gk. verb to write) and it lies in a strip between tentative theory stage and error elimination stage. The issue at point is how fairly the researcher represents the experiences. Take the case of children's experience. We educationalists regard them as almost sacred because we know that they are unique, culturally 
permeated, immanent and non-transferable. When a researcher describes children's experiences, it implies that sense-data undergo a second interpretive intervention (first being that of children's) and this implies in turn an unavoidable distortion. Thomas Nagel (1974) pointed out an epistemological problem of mind-body theorization, suggesting that an alien experience, be it that of a bat or person, is incommensurable for outsiders, and that radical reductionists and physicalists cannot possibly articulate any credible epistemology apart from their own, and perhaps not even their own. A solution to this problem of disparity between phenomenon and graphein, in my view, is openly and systematically revealing the variation between the experience-description of research participants and the experience-description of the researcher. Indeed, this is the sort of gap that phenomenography has been trying to bridge for three decades in education (Marton 1981) (Marton 1988) (Pang 2003). What is relevant to the present argument on research in and with $\mathrm{CHC}$ is not phenomenography qua pedagogical tool (Marton's original project) but its use of variation as research methodology. Only an inclusion of variation factor can break the interpretive monopoly of researcher. Emi/etic variation comes into view through behaviour, which in turn depends significantly on culture. A CHC-based educational research should take into account the association between behavioural patterns and culture. When $\mathrm{CHC}$ students see a fish tank picture, for example, they attribute the movement of fish to the environment and other animals in the fish tank, whereas Western students attribute it to the fish themselves. Using similar experiments Nisbette et al. (2005; 2001) argued that significant variation exists between the two groups, which seems essential for data analysis in CHC-based research:

East Asians [are more] holistic, attending to the entire field and assigning causality to it, making relatively little use of categories and formal logic, and relying on "dialectical" reasoning. Westerners are more analytic, paying attention primarily to the object and the categories to which it belongs and using rules, including formal logic, to understand its behavior. (2001, p. 291)

Empirical findings of Nisbette et al. suggest that CHC informs behaviour on the surface, at the same time that it informs underlying metaphysical categories (e.g., accidentsubstance, essence-existence) and epistemological processes including believes and values. Jin Li's empirical research findings (2002) somewhat corroborate Nisbette's. CHC children's belief on learning and their motivation to learn depend more on the culturally created plus valuation of te (德 virtues) such as diligence and personal effort 
rather than on Western model that values more talent, innate smartness and biological basis of intelligence. It is in this light that parental socialization appears as a powerful influence on CHC children's educational values and attitudes, with epistemological consequences. In my view, research on CHC students should ideally include information/data from parents.

Solving the problem of disparity between phenomenon and graphein inherent to cross-cultural and international comparative education research won't placate the emic-etic tension completely. The reason is that a phenomenon and graphein inequality presupposes an intrusion, cultural intrusion and disempowering, without actually solving it. And it is Freire who suggests a solution and candidly:

"In cultural invasion the actors...superimpose themselves on the people, who are assigned the role of spectators, of objects. In cultural synthesis, the actors become integrated with the people, who are co-authors of the action that both perform upon the world" (1972, p. 147).

\section{The Possibility of an Asian Educational Research Methodology}

To conclude, for CHC-based education researches, neither 'Eastern' nor 'Western' conceptual and theoretical frameworks are to be dismissed in a Popperian error elimination fashion. They are not totally incommensurable à la Kuhn (1970), furthermore, they clearly share more in common than we would admit at first sight.

The Confucian Heritage Culture as an academic discourse is relatively short. An ad hoc research methodology in and about $\mathrm{CHC}$ would be an impossible were it to attempt bypassing Western research rigor. Yet, Asian education research methodology in and about CHC could be recognized as a particularly nuanced methodology in education subject to certain conditionals:

1. Adopted research problem and theoretical framework should not neglect to articulate a thick conception of $\mathrm{CHC}$ as opposed to a thin conception of it. Without it, calling nation-states by their names should be preferred over nicknaming and bundling them up as $\mathrm{CHC}$;

2. CHC-based research methodology issues are largely ethical issues that derive from interpersonal relationship among research actors. Education research without understanding re (Korean), li (Chinese) or shikata (Japanese) is 
likely to generate problems, such as low collaboration, unauthentic information, bilateral apprehension and avoidance;

3. Any CHC-based research dynamics and Western research dynamics are not mutually exclusive. Ad casum methodological nuances should be addressed in a case-to-case basis;

4. Any possible 'Asian education research methodologies' in and about $\mathrm{CHC}$ should ideally be methodologies that take into account the phenomenographic variation between experience and description of educational realities, as well as the issue of cultural invasion.

\section{References}

Adler, Nacy J., and Anne-Wil Harzing. 2009. When Knowledge Wins: Transcending the Sense and Nonsense of Academic Rankings. The Academy of Management Learning and Education (AMLE) 8 (1):72-95.

Ama, Toshimaro. 2005. Why are the Japanese non-religious? : Japanese spirituality : being non-religious in a religious culture. Lanham, Md.: University Press of America.

Banville, Dominique, Pauline Desrosiers, and Yvette Genet-Volet. 2000. Research Note. Translating Questionnaires and Inventories Using a Cross-Cultural Translation Technique. Journal of Teaching in Physical Education 19 (3):374-87.

Behling, Orlando, and Kenneth S. Law. 2000. Translating questionnaires and other research instruments : problems and solutions, Sage university papers series. Quantitative applications in the social sciences. Thousand Oaks: Sage Publications.

Berry, John W. 1969. On Cross-Cultural Comparability. International Journal of Psychology 4 (2):119-128.

- 2003. Conceptual approaches to acculturation. In Acculturation : advances in theory, measurement, and applied research, edited by K. Chun, P. B. Organista and G. Marín. Washington, D.C.: American Psychological Association.

Biggs, John B., David Watkins, Comparative Education Research Centre., and Australian Council for Educational Research. 1996. The Chinese learner : cultural, psychological and contextual influences. Hong Kong: Comparative Education Research Centre. 
Bishop, Alan J. 1988. Mathematical enculturation : a cultural perspective on mathematics education. Dordrecht: Kluwer Academic Publishers.

Bourdieu, Pierre, and Jean Claude Passeron. 1977. Reproduction in education, society and culture. 2nd ed, Theory, culture \& society. London: Sage.

Brashen, Henry M. 1974. Research Methodology in Another Culture: Some Precautions. Paper read at Annual Meeting of the International Communication Association. April 17-20, 1974, at New Orleans, Louisiana.

Bridges, David. 2001. The Ethics of Outsider Research. Journal of Philosophy of Education 35 (3):371-386.

Brislin, R. W. 1986. The wording and translation of research instruments. In Field methods in cross-cultural research, edited by W. Lonner and J. Berry. Beverly Hills, CA: Sage.

Bruner, Jerome S. 1996. The culture of education. Cambridge, Mass.: Harvard University Press.

Chan, Carol K. K., and Nirmala Rao. 2009. Revisiting the Chinese learner : changing contexts, changing education. Hong Kong: Comparative Education Research Centre, The University of Hong Kong.

De Mente, Boye. 2005. Japan unmasked : the character and culture of the Japanese. Boston, Mass.: Tuttle Publishers Group Worldwide.

Eisner, Elliot W. 1985. The art of educational evaluation : a personal view. London: Falmer Press.

Evers, C. W., and Gabriele Lakomski. 2001. Theory in educational administration: naturalistic directions. Journal of Educational Administration 39 (6):499-520.

Fingarette, Herbert. 1972. Confucius : the secular as sacred. New York: Harper \& Row. . 1979. The Problem of the Self in the Analects. Philosophy East and West 29 (2):129-140.

Freire, Paulo. 1972. Pedagogy of the oppressed. London: Penguin Books.

Funabashi, Yoichi. 1993. The Asianisation of Asia. Foreign Affairs 72 (5):75-85.

Gao, Fang. 2010. Becoming a model minority : schooling experiences of ethnic Koreans in China. Lanham, Md.: Lexington Books.

Hattie, John. 2009. Visible learning : a synthesis of over 800 meta-analyses relating to achievement. London; New York: Routledge.

Ho, David Y. F. 1994. Cognitive Socialization in Confucian Heritage Cultures. In Crosscultural roots of minority child development, edited by P. M. Greenfield and R. R. Cocking. Hillsdale, N.J.: L. Erlbaum Associates.

Hofstede, Geert H. 1991. Cultures and organizations : software of the mind. London: 
McGraw-Hill.

Kant, Immanuel. 1997. Critique of practical reason. Translated by M. J. Gregor, Cambridge texts in the history of philosophy. Cambridge, U.K.: Cambridge University Press.

- 2006. Anthropologie in pragmatischer Hinsicht / Anthropology from a pragmatic point of view. Edited by R. B. Louden. Cambridge, UK ; New York :: Cambridge University Press.

Kuhn, Thomas S. 1970. The structure of scientific revolutions. 2d ed. Chicago,: University of Chicago Press.

- 1977. The Essential tension : selected studies in scientific tradition and change. Chicago: University of Chicago Press.

LeVine, Robert A. 1966. Outsiders' Judgments: An Ethnographic Approach to Group Differences in Personality. Southwestern Journal of Anthropology 22 (2):101116.

Li, Jin. 2002. A Cultural Model of Learning: Chinese "Heart and Mind for Wanting to Learn". Journal of Cross-Cultural Psychology 33 (3):248-269.

- 2003. The Core of Confucian Learning. American Psychologist 58 (2):146-147.

- 2009. Learning to Self-Perfect: Chinese Beliefs about Learning. In Revisiting the Chinese learner : changing contexts, changing education, edited by $\mathrm{C} . \mathrm{K} . \mathrm{K}$. Chan, N. Rao and Comparative Education Research Centre. Hong Kong: Comparative Education Research Centre, The University of Hong Kong.

Liu, Shuxian. 1998. Understanding Confucian philosophy : classical and Sung-Ming. Westport, Conn. ; London: Greenwood Press.

Lowe, Lisa. 1996. Immigrant acts : on Asian American cultural politics. Durham, NC: Duke University Press.

Marton, Ference. 1981. Phenomenography-Describing conceptions of the world around us. Instructional Science 10 (2):177-200.

- 1988. Phenomenography : a research approach to investigating different understandings of reality. In Qualitative research in education : focus and methods, edited by R. R. Sherman and R. B. Webb. London: Falmer Press.

Mason, Mark. 2007. Comparing Cultures. In Comparative Education Research: Approaches and Methods, edited by M. Bray, B. Adamson and M. Mason. Hong Kong: Comparative Education Research Centre Springer.

Nagel, Thomas. 1974. What Is It Like to Be a Bat? The Philosophical Review 83 (4):435-450.

Nind, Melanie, Shereen Benjamin, Kieron Sheehy, Janet Collins, and Kathy Hall. 2004. 
Methodological Challenges in Researching Inclusive School Cultures. Educational Review 56 (3):259-270.

Nisbett, Richard E., and Yuri Miyamoto. 2005. The influence of culture: holistic versus analytic perception. Trends in Cognitive Sciences 9 (10):467-473.

Nisbett, Richard E., Kaiping Peng, Incheol Choi, and Ara Norenzayan. 2001. Culture and Systems of Thought: Holistic Versus Analytic Cognition. Psychological Review 108 (2):291-310.

Pang, Ming Fai. 2003. Two Faces of Variation: on continuity in the phenomenographic movement. Scandinavian Journal of Educational Research 47 (2):145-156.

Park, Insook Han, and Lee-Jay Cho. 1995. Confucianism and the Korean family. Journal of Comparative Family Studies 26 (1):117-134.

Polanyi, Michael. 1983. The tacit dimension. Gloucester, Mass.: Peter Smith.

Popper, Karl Raimund. 1959. The logic of scientific discovery. London: Hutchinson.

- 1963. Conjectures and refutations : the growth of scientific knowledge. London: Routledge and Kegan Paul.

- 1972. Objective Knowledge - an evolutionary approach. Oxford: Oxford University Press.

- 1999. All life is problem solving. London; New York: Routledge.

Rozman, Gilbert. 2002. Can Confucianism Survive in an Age of Universalism and Globalization? Pacific Affairs 75 (1):11-37.

Stove, D. C. 1982. Popper and after : four modern irrationalists. Oxford: Pergamon Press.

Taylor, Peter C., and Bruce G. Waldrip. 1999. Standards for Cultural Contextualization of Interpretive Research: A Melanesian Case. International Journal of Science Education 21 (3):249-60.

Tweed, Roger G. , and Darrin Lehman. 2002. Learning Considered Within a Cultural Context: Confucian and Socratic Approaches. American Psychologist 57 (2):8999.

Vallerand, Robert J. , Luc G. Pelletier, Marc R. Blais, Nathalie M. Briere, Caroline Senecal, and Evelyne F. Vallieres. 1992. The Academic Motivation Scale: A Measure of Intrinsic, Extrinsic, and Amotivation in Education. Educational and Psychological Measurement 52:1003 - 1017.

Waley, Arthur, and Confucius. 1938. The Analects of Confucius. London: George Allen \& Unwin Ltd.

Wang, Gungwu. 2001. Don't leave home : migration and the Chinese. Singapore: Times Academic Press. 
Watkins, David, John B. Biggs, and Comparative Education Research Centre. 2001. Teaching the Chinese learner : psychological and pedagogical perspectives. Hong Kong: Comparative Education Research Centre, University of Hong Kong. Watkins, David, Murari Reghi, and Estela Astilla. 1991. The-Asian-learner-as-a-rotelearner Stereotype: myth or reality? Educational Psychology: An International Journal of Experimental Educational Psychology 11 (1):21-34.

Whitehead, Alfred North. 1967. The aims of education, and other essays. 1st Free Press paperback ed. New York: Free Press. 